\title{
INDUSTRIAL AUTOMATION
}

$\mathrm{T}$ HE fifty-two industrial research associations in Britain have long been an integrated network of research organizations stretching across more than 60 per cent of the country's productive industry. The first formal step in this integration was the agreement, some years ago, that as a matter of policy all research associations should be encouraged to assist one another and, through each other, their industrial members with advice and guidance on technological problems. Each association is thus able to draw on a wide range of technological skills beyond its own. This integration has been fostered, too, by the formation of groups of research associations having similar or related technologies. Thus we have a Committee of Directors of Textile Research Associations and similar groups for the metal and food industries. These groups meet for the exchange of views, for mutual assistance and for the avoidance of unnecessary duplica. tion of research work. Among the textile research associations, collaboration has now reached a point where each association allocates a small proportion of its annual budget to collaborative work of interest to more than one industry. Collaborative enterprises at present include investigations into flame-proofing and into the purification and disposal of effluents and the conservation of water.

A further step was announced on February 6 with the formation by the Committee of Directors of Research Associations of an Industrial Automation Group. This new step has been taken because it is believed that, since rapid progress in the application of automation depends largely on the exchange of information and co-operation between those with expert knowledge of control engineering and those with expert knowledge of particular production technologies and problems, the research associations have a unique part to play. They are already aware of the manufacturing problems of the industries they serve and know of the trends of development taking place in them. The great diversity of problems that exists in different industries makes it especially appropriate that the research associations, integrated as they are and in partnership with Government through the Department of Scientific and Industrial Research, should be expected to play a major part in the future application of automation to industry. Some research associations have already made valuable contributions to the general application of automation procedures both by developing improved machinery and automatic control devices, and by encouraging and assisting their members to apply automation concepts.

The objectives of the new Industrial Automation Group may be summed up as the acceleration of the introduction of automation techniques. To this end it proposes to assist all research associations to set up automation sections; to formulate automation projects or their components that are of common interest to a number of research associations and that would benefit from joint action; to assist in utilizing each research association's specialist facilities related to automation; and to provide a mechanism through which collaborative activities with a bearing on automation can be fostered. It is hoped, too, that the Group will be able to negotiate special financial support from the Government for the promotion of automation projects. It is expected that the Group will be able to encourage the development of specialist automa. tion projects in the research associations and, through them, in their respective industries by providing a channel of communication between the associations, by conferences and special lectures or demonstrations, and by forging links with professional and technical organizations with similar objectives.

It is intended, initially at least, that the interests of the Industrial Automation Group shall be confined to technical and economic problems. The Committee sponsoring the Group is, of course, aware of the fears that have been expressed about the social consequences that may follow in the wake of the widespread application of automation but is satisfied that such questions are already the concern of other bodies better able to deal with them.

The first meeting of the Industrial Automation Group was held in December when a start was made on the formulation of projects, based on present-day work in the research associations, suitable for collaborative efforts. For example, two years of preliminary research and development at the British Launderers' Research Association have proved the feasibility of auto-racking and packing of customers' bundles of finished laundry. With the addition of a marking system suitable for automatic reading and identification, simplified magnetic data. storage devices for customer information and automatic pricing of bundles on the basis of weight and number of articles (all of which is now under active development), visual identification and manual sorting will be unnecessary. It is easy to see the possible extension of such a development, if successful, into the fields of central engineering stores, mail-order houses, parcel sorting, many forms of packaging, warehousing and dispatching.

At the Warren Spring Laboratory of the Department of Scientific and Industrial Research, which is also represented on the Group, a considerable amount of work is now in progress to apply computers to the control and optimization of chemical and other plant. Provided the problems associated with the provision of suitable measuring devices can be solved it will be possible to apply the technique to a wide variety of processes, the only additional work in each instance being the establish. ment of a suitable sample technique. The generalization of techniques in this way and the cross-fertilization of technologies, as illustrated by the laundry project, will be an essential function of the Industrial Automation Group.

The chairman of the Group is S. S. Carlisle of the British Seientific Instrument Research Association, and the Machine Tool, Hosiery, Baking, Launderers' and Cotton Silk and Man-made Fibres Research Associations are all represented on it, together with the Warren Spring Laboratory; the United Kingdom Automation Council is represented by J. F. Coales, its chairman.

D. W. HiLL

\section{TRADE UNIONS: THE SECOND CALL TO REFORM}

S a complement to an earlier Broadsheet Trade Unions
which discussed the scope for trade union activity to-day
and in the future, Political and Economic Planning has
continued its study of Trade Unions with a further Broad-
sheet entitled The Structure and Organization of British
Trade Unions*. In this latest Broadsheet, B. Donoughue, A. Oakley and Janet Alker seek to establish in what ways Union structure and organization are not working effici-

* Planning, 29, No. 477; December 2, 1963. The Structure and Organsza. tion of British Trade Unions. Pp.431-486. (London: Political and Economic Planning, 1963.) 58. 
ently to-day and are inadequate to carry out both traditional Union functions and the newer functions which will become increasingly important. Secondly, they set out to consider practical steps by which reforms and improvements might be introduced.

Three main groups of problems are distinguished. First, those concerning the structure of the British Trade Union movement, such as the inefficiencies and difficulties arising from the existence of hundreds of autonomous Unions. Secondly, those concerning communication and control within individual Unions; and, thirdly, those concerning the Trades Union Congress itself, such as its weaknesses as a central co-ordinating body of the movement. The Broadsheet emphasizes that most of the problems examined do not exist everywhere, affecting some industries and some Unions much more than others: the whole Trade Unions movement is not to be condemned for the shortcomings of certain parts of it.

While the approach and diseussion are thoroughly realistic and include numerous constructive suggestions, it is pointed out that the final answers must come from those with direct experience and responsibility: the Broadsheet does not pretend to offer more than some contribution to a better understanding of the present issues and of some possible ways of reform and the likely obstacles. Nevertheless, it leaves no room for doubt that something more than tinkering with organization is required. A different economic system is already in the making and the real question is whether the prosent structure and practice of British Trade Unionism are such as to help or hinder the growth of a planned econornic system. None of those concerned can foresee how the process will develop, but that does not exempt any of them Government, industry, workers, financiers and economists -from the necessity of showing some foresight in guiding their particular steps with intelligence and purpose towards the common goal. In particular, it does not exempt the Trade Union movement from directing any changes in its present structure and practice into ways that would meet the evident needs of a planned system, so that in the process the movement may acquire its rightful and responsible part in shaping that new system. This implies that the Trade Union movement must take early steps to acquaint itself with the real facts of modern economic life and to disseminate that knowledge from the point of view of its own members' interests. Nor is a national planned policy possible with hundreds of Unions pulling different strings in different directions: to carry the weight and influence in national affairs to which it is entitled the movement must find ways of weaving those many strings into one powerful rope.

The Broadsheet is written with sympathy as well as insight and is a contribution to the informed discussion of current affairs which strengthens the hands of those Trade Union leaders who are already working for reform, and one for which the whole movement should be grateful.

\section{FUTURE OF TOWN GAS}

$\mathrm{T}$ OWN gas first originated from coal and it is now one hundred and fifty years ago that the first British commercial gas enterprise, the London and Westminster Gas Company, was founded. This concern established three gas-producing stations, laid initially fifteen miles of mains, was responsible for the first gas lamps on Westminster Bridge, and later, during the Victorian age, exercised much influence on the rapid expansion of the gas industry throughout Britain. The famous invention of the Welsbach incandescent gas mantle in 1887 revolutionized the efficiency of gas lighting everywhere, but this innovation came a little too late. The advent of electric lighting in 1882 sponsored a challenge to coal-gas as a source of lighting and heating which, although not fully appreciated at that time, was destined to win the battle for lighting, but certainly not for heating, for which purpose the use of gas has progressively increased. Between the First and Second World Wars the increasing competition from electricity determined radical changes in the gas industry which, by 1939, had become mainly a supplier for heating and cooking. Then came the Gas Act of 1948 which nationalized the entire industry, the basic pattern now clearly discernible, much as is the case with nationallized electricity as experienced to-day. The central controlling body is the Gas Council, appointed by the Ministry of Power, and in its annual report, surveying recent advances and new techniques of gas production, it states of the latter: "The most striking of these has been the rapid development and commercial application of the industry's research into the production of gaseous hydrocarbons by the hydrogenation and the reforming of petroleum oils".

The early process for making gas was by heating coal in iron or fire-clay retorts, and subject to many refinements evolved over the years this prineiple was followed for more than a century. The residual coke posed a problem until a process was developed whereby 'water gas' was manufactured; this depended on the chemical reaction set up by passing steam through beds of hot coke, resulting in decomposition of the steam into hydrogen and carbon monoxide; as the temperature fell, air was introduced into the system and more heat thus raised. Water gas produced by this eyclic action does not possess a high calorific value (about 300 B.Th.U. per cubic foot); it has to be enriched and this is achieved by the use of gas oil derived from petroleum. Gas oil is similar to Diesel oil in characteristics; it was originally called 'gas oil' because of its use in gas production. This form of enrichment resulted in a gas having about $500 \mathrm{~B}$.Th.U. per cubie foot, much the same calorifie value as gas manufactured direct from coal.

Further research on the complete gasification of coal, leaving nothing but ash, was commercially developed on the Continent after the end of the Second World War. According to an article in a recent issue of Esso Magazine (13, No. 1; Winter 1963-64), entitled "Gas from Oil": "One of the most successful methods of complete gasification is the Lurgi process in which coal is reacted with steam and oxygen. . . . This process is attractive because relatively poor quality coal can be gasified. But, again, the gas produced by the Lurgi method is not suitable for feeding directly into town gas distribution systems. It, too, has to be enriched by oil. . . . The real revolution in gas-making is not primarily a result of advances in making gas from coal but in making gas from oil'". Herein lies the crux of the present situation in the gas industry: its dependence more and more on the petroleum industry. Whereas in the past the only oil feedstock used in the gas industry was gas oil, nowadays feeding stocks include propane, butane, refinery gas, naphtha, and heavy fuel oils.

Since 1955 the gas industry has constructed some fifty plants for converting fuel oils into town gas. Although different types of plant are involved the basic processes used are similar and consist of passing steam and hydrocarbon vapours through a bed of hot catalyst whereby gas is produced. Further developments have resulted in the building of what are known as continuous catalytic conversion plants: that designed by Imperial Chemical Industries, Ltd., is stated in Esso Magazine to be smong the most efficient. But gas made from this proeess still has to be enriched. To give effect to this economically, a 